\title{
Congenital Anomalies of Inferior Vena Cava, Review of Embryogenesis, Presentation, Associated Congenital Anomalies and Surgical Importance
}

\author{
Neelam desai*, Nageswar Rao J, Aaditya sirohi and Deepak Gowda
}

Department of Ctvs, Sri Satya Sai institute of higher medical sciences, Prasanti gram, Puttaparthi, Andhra Pradesh, India

Received: 04 December, 2017; Accepted: 22 January, 2018; Published: 29 January, 2018

*Corresponding author: Neelam desai, Department of Ctvs, Sri Satya Sai institute of higher medical sciences, Prasanti gram, Puttaparthi, Andhra Pradesh, India, E-mail: neelsai@gmail.com

\begin{abstract}
Background: Congenital variation of inferior vena cava is caused by abnormal embryological development, they are associated with situs inversus, polysplenia and congenital heart diseases. Our aim is to evaluate embryogenesis, presentation, diagnostic modalities and its surgical importance in case of interrupted inferior vena cava with congenital heart disease.
\end{abstract}

Materials and Methods: 14 cases of interrupted inferior vena cava have been reported till now. Out of these cases one case had congenital heart defect and underwent surgical correction. We are going to discuss two cases of interrupted inferior vena cava operated for congenital heart defects in our institute, embryogenesis of defect, the diagnostic modalities used, surgical technique followed and outcome of surgeries and compare them with previously reported cases. First case was a 10 year old boy diagnosed with Gerbode ventricular septal defect, large atrial septal defect, atrial isomerism, persistant left superior vena cava, heterotaxy, polysplenia, duplicated and interrupted inferior vena cava with azygos continuation .Second case was 17 year old boy diagnosed with tetra logy of fallot, interrupted inferior vena cava with azygous continuation, heterotaxy, polysplenia.

Results: Out of previously reported cases two cases underwent surgery, one patient underwent partial anomalous pulmonary venous connection correction and the other patient underwent segmentectomy of carcinoma lung. Remaining previously reported cases were either detected incidentally or were detected during post mortem. Both our patients underwent surgical correction, first patient developed pericardial effusion post operatively, both patients discharged in stable condition, and pre-discharge echocardiography showed normal biventricular function, and awaiting follow up after three months.

Conclusion: Interrupted inferior vena cava can be diagnosed with 2dimensional echocardiography, angiography and confirmed with computed tomography scan and magnetic resonance imaging Preoperative diagnosis of interrupted inferior vena cava helps in planning for surgeries involving cardiopulmonary bypass and surgeries involving thoracotomy. It also helps in management of associated diseases like deep vein thrombosis.

Keywords: Interrupted Inferior Vena cava; Heterotaxy; Azygos; Hemiazygos

\section{Introduction}

Congenital variation of inferior vena cava is caused by abnormal embryological development. These variations are usually clinically asymptomatic. They get detected incidentally during radiological investigations done for patient undergoing surgery.

Congenital anomalies in the Inferior Vena Cava (IVC) have been reported in $0.3 \%$ of population and in $0.6-2 \%$ of patients with other cardiovascular defects [1]. Absence of the hepatic segment of the IVC, with azygos continuation into right Superior Vena Cava (SVC) has been reported as an incidental finding at postmortem examinations since 1793[1-6].

Till today 14 cases of interrupted IVC have been reported, out of them one had Partial Anomalous Pulmonary Venous Connection (PAPVC) with Atrial Septal Defect (ASD) and underwent surgical correction with good result, 2 cases were detected on post mortem, rest of cases were diagnosed incidentally. In all the above studies surprisingly only one case had an associated cardiac anomaly, while all other were isolated cases of interrupted IVC, unlike our cases which had congenital cardiac anomalies.

We report two such cases of interrupted IVC in cases of congenital heart diseases. The IVC malformations were detected during 2 Dimensional Echocardiography (2D ECHO). The heterotaxy was detected by pre op $\mathrm{x}$ rays. Ultrasound and Computed Tomography (CT) scan were done for academic purpose. The origin of variation, possible complications, rare presentations and possible misdiagnosis are discussed in this case report.

\section{Material and Methods}

We are going to discuss our two cases of interrupted IVC and compare the presentation, associated congenital anomalies, diagnostic modalities used, surgery done and outcome with the previously reported cases (Table 1). 
Congenital Anomalies of Inferior Vena Cava, Review of Embryogenesis, Presentation, Associated Congenital Anomalies and Surgical Importance

\begin{tabular}{|c|c|c|c|c|c|}
\hline Study & Age & Sex & Diagnosis & Investigations & Surgery \\
\hline Loukas M, et al. (2009) & 59 & Female & Interrupted IVC & Post Mortem & - \\
\hline $\begin{array}{l}\text { Fulcher and Turner (2002). } 7 \\
\text { cases }\end{array}$ & unavailable & unavailable & Interrupted IVC & & \\
\hline Truba R, Hribernik M(2002) & 40 & Female & Interrupted IVC & Post Mortem & - \\
\hline Hardwick T, et al.(2011) & 69 & Female & $\begin{array}{l}\text { CA lung and } \\
\text { Interrupted IVC }\end{array}$ & CT scan & Segmentectomy \\
\hline Colak, et al. (2009) & 38 & Female & $\begin{array}{l}\text { PAPVC ASD Interrupted } \\
\text { IVC }\end{array}$ & CT scan & $\begin{array}{l}\text { ASD closure and } \\
\text { PAPVC correction }\end{array}$ \\
\hline \multirow{3}{*}{ Angelika NF, et al (2014)- 3 cases } & 15 & Female & \multirow{3}{*}{$\begin{array}{c}\text { Deep vein } \\
\text { thrombosis(DVT) } \\
\text { Interrupted IVC }\end{array}$} & \multirow{3}{*}{ CT scan } & \\
\hline & 17 & Male & & & \\
\hline & 16 & Male & & & \\
\hline \multirow[b]{2}{*}{ Our cases } & 10 & Male & \multirow{2}{*}{$\begin{array}{c}\text { CHD, Interrupted IVC, } \\
\text { Heterotaxy, } \\
\text { Polysplenia }\end{array}$} & \multirow{2}{*}{$\begin{array}{c}\text { 2D ECHO } \\
\text { Angiography }\end{array}$} & \multirow{2}{*}{$\begin{array}{c}\text { Surgical correction } \\
\text { for congenital heart } \\
\text { disease. }\end{array}$} \\
\hline & 17 & Male & & & \\
\hline
\end{tabular}

Abbreviations: ASD- Atrial Septal Defects, CA lung - Carcinoma lung, CHD-Congenital Heart Disease, CT -Computed Tomography, 2D ECHO-2 Dimensional Echocardiography, IVC-Inferior Vena Cava, PAPVC- Partial Anomalous Pulmonary Venous Connection

\section{Case Report}

Case 1: A 10 year old boy admitted with complaints of repeated respiratory tract infections, and stunted growth. Clinical examination pointed towards congenital heart disease which was confirmed by echocardiography. It was a case of Gerbode Ventricular Septal Defect (VSD), large ASD, Left Atrial Isomerism and persistent Left Superior Vena Cava (LSVC). ECHO confirmed the diagnosis of interrupted IVC. Pre operative chest $\mathrm{x}$ ray created doubt when fundic shadow was seen below right dome of diaphragm (Figure 1). The angiography showed interrupted IVC and CT scan showed in figure $2 \mathrm{~A}, \mathrm{~B}, \mathrm{C}$ double IVC, with continuation of azygos vein on the right, with heterotaxy and polysplenia. Hemiazygos vein was seen joining the azygos at D9 level. Azygos vein seen draining into the SVC at the level of carina. Hepatic veins drained separately into the right atrium. Persistent Left sided SVC drained into the coronary sinus.

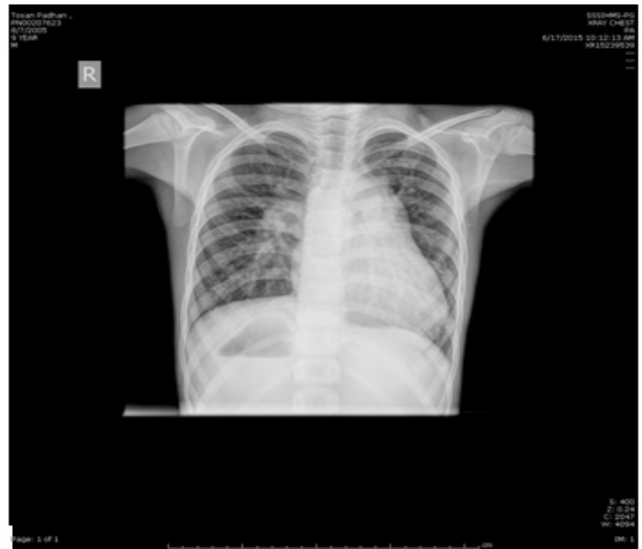

Figure 1: Shows- Situs ambiguous with gastric shadow on right (Patient 1)

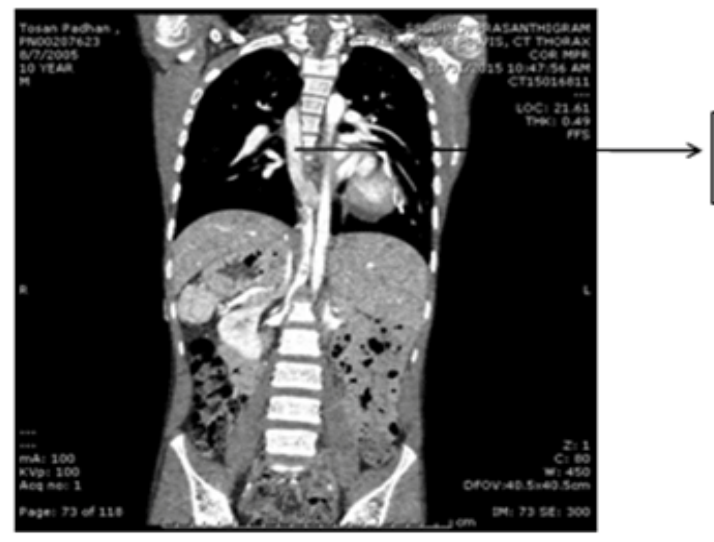

Azygous continuation of IVC

opening into Superior vena cava

Figure 2a: Angiography showed interrupted IVC and CT scan 


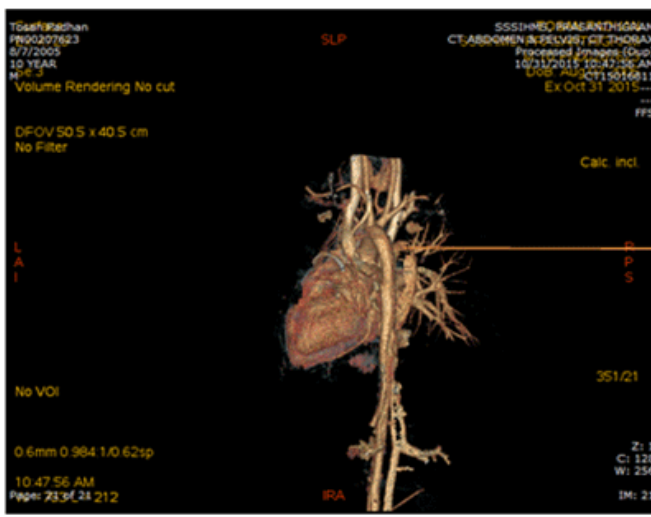

Figure 2b: Angiography showed interrupted IVC and CT scan

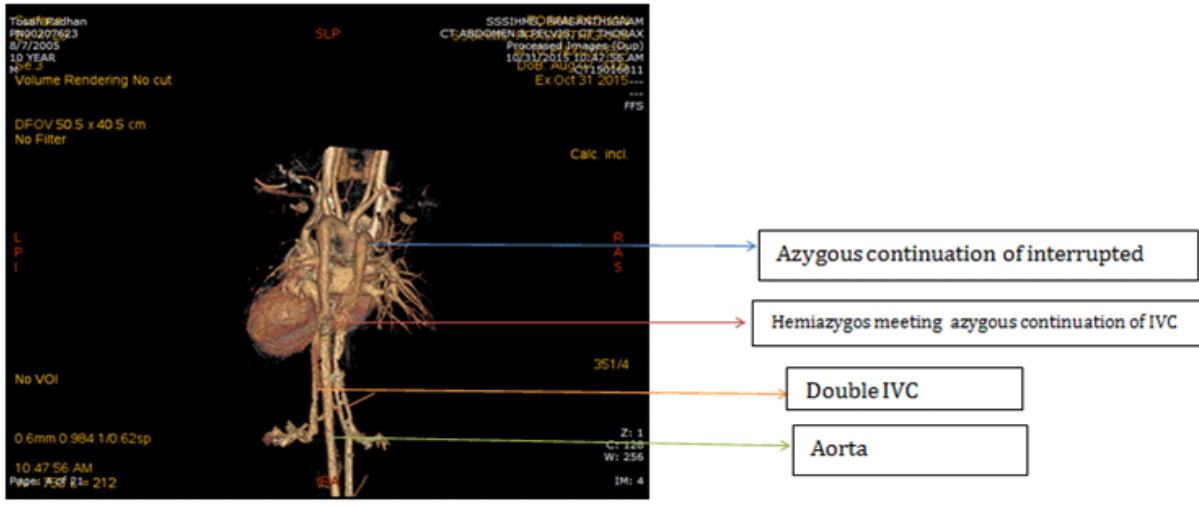

Figure 2c: Angiography showed interrupted IVC and CT scan

Surgical Findings and Procedure: Large OS ASD, LSVC draining into coronary sinus, large Gerbode type of VSD were noted. Interrupted IVC \& azygos continuation of IVC seen and anatomy studied. For cannulation number 20 straight cannula was put in RSVC, number 20 straight cannula was put in LSVC through coronary sinus. Number 20 angled cannula was put in IVC. VSD closed with autologous untreated pericardial patch using 5-0 interrupted \& continuous pledgetted sutures through RA. ASD OS was closed with autologous untreated pericardial patch using 5-0 prolene suture.

Case 2: 17 year old boy, came with complaint of cyanosis since birth and dyspnea on exertion. Patient had cyanosis and clubbing. Diagnosed with Tetra logy of Fallot and patent ductus arteriosus. Pre operative $x$ ray showed fundic shadow on right and interrupted IVC was diagnosed during 2D ECHO and angiography CT scan clearly showed figure 3 presence of interrupted IVC and features of situs inversus.

Surgical Findings and Procedure: Findings noted were Interrupted IVC \& Azygos continuation of IVC, perimembranous VSD with about $90 \%$ aortic override, tight fibrous pulmonary OS.

Apart from the routine initial steps. SVC was cannulated by large sized cannula. Main pulmonary artery (MPA) was dissected

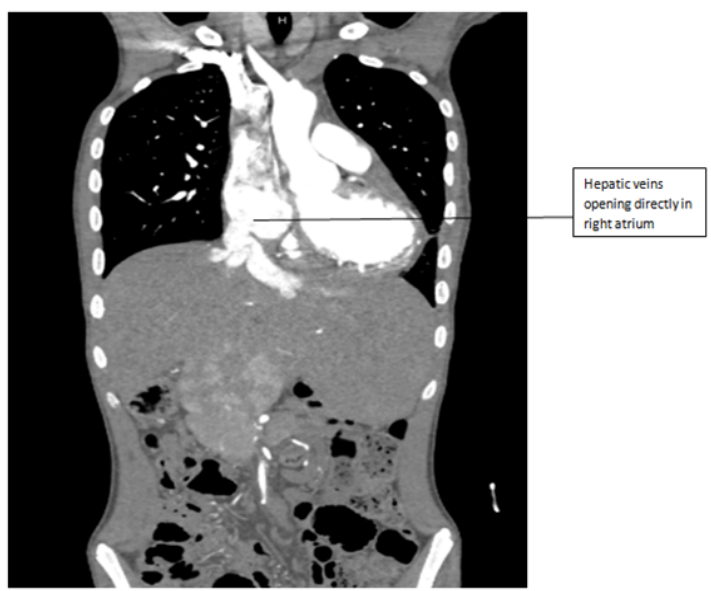

Figure 3: CT scan

from the aorta. After satisfactory arrest, cavae were snugged \& right atrium opened. Left ventricle vented through surgically created septal defect. After assessing the anatomy, infundibular resection was done \& fibrous OS excised through RA, RVOT sized to 22 hegars. The VSD was enlarged anterosuperiorly \& closed with a piece of $16 \mathrm{~mm}$ Haemashield tube graft. 
Postoperative ECHO of case 1 showed intact ASD and VSD patch and mild circumferential pericardial effusion, 4-5 mm posteriorly and laterally, pigtail catheter was inserted and fluid drained. After removal of pigtail catheter ECHO repeated and showed no fluid and good biventricular function.

Postoperative ECHO of case 2 showed intact VSD patch and good biventricular function.

The pre operative detection of interrupted IVC helped in going into cardio pulmonary by pass without any difficulty. After surgery both patients were discharged in stable condition.

Out of previously reported 14 cases, 1 case had congenital heart diseases, 1 patient had carcinoma lung \& remaining 12 cases were not associated with any cardiac or lung anomaly they were diagnosed either incidentally or during postmortem. The case with PAPVC and ASD was successful and patient was discharged in stable condition.

The patient with Carcinoma lung underwent segmentectomy and was also discharged in stable condition.
Three cases reported had DVT, all were in pediatric age group and were managed medically.

\section{Discussion}

Embryological development of venous system starts as early as fifth week. Major veins distinguished during that time are

1. Vitelline vein or omphalomesenteric veins, carrying blood from the yolk sac to the sinus venosus

2. The umbilical veins, originating in the chorionic villi and carrying oxygenated blood to the embryo

3. The cardinal veins, draining the body of the embryo proper

The development of normal inferior vena cava begins during 6th week of gestation and continues up to 8th week (Figure 4). Development begins with three pairs of embryonic veins: the posterior cardinal, subcardinal and the supracardinal veins. This is followed by a cyclical process of development and regression, which eventually culminates into the permanent asymmetric inferior vena cava [2].

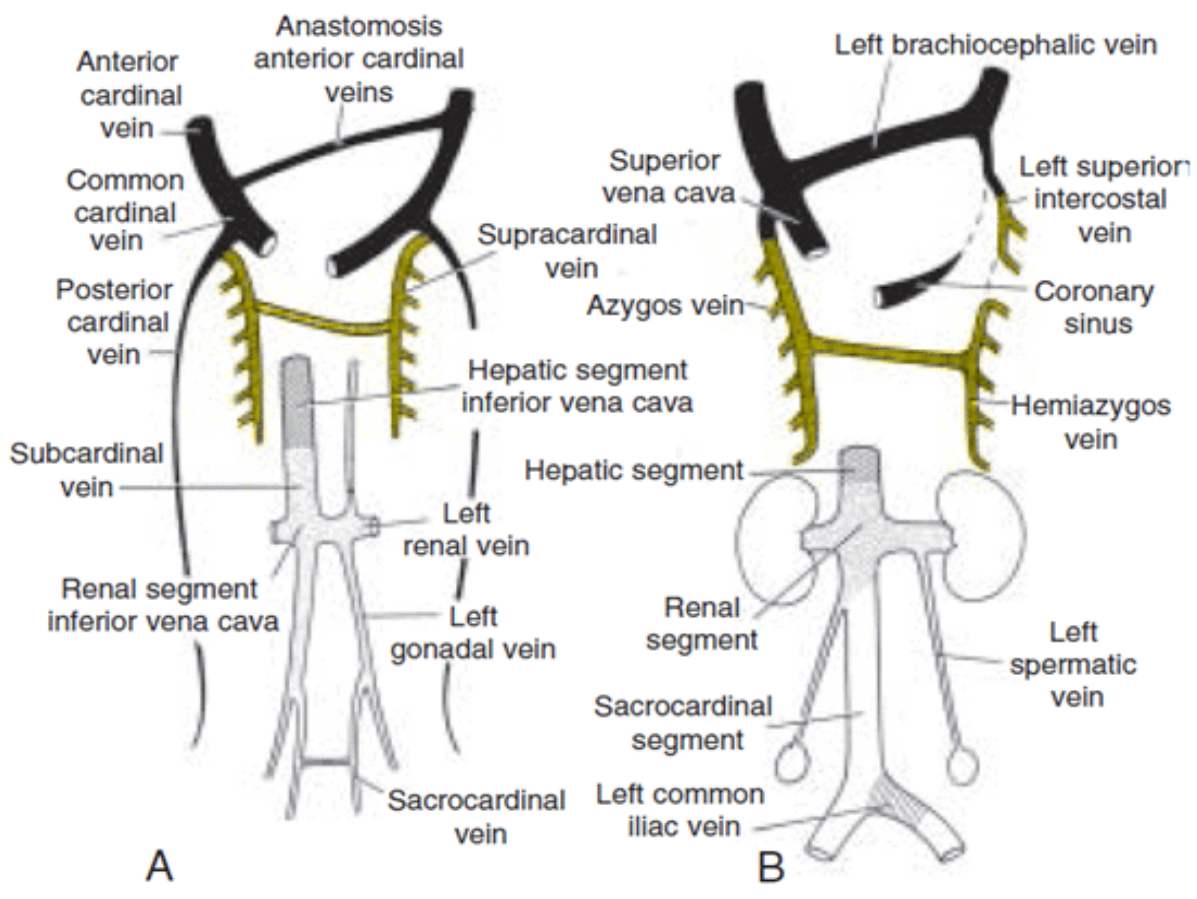

Figure 4: Inferior Vena Cava

The right and left subcardinal veins form an inter-subcardinal anastomosis while an anastomosis forms between the subcardinal veins and the posterior cardinal veins. The hepatic vein joins with right subcardinal vein to form vitelline vein. Eventually the prerenal division of the IVC is formed by the progressive degeneration of the posterior cardinal veins, therefore shunting blood through the hepatic segment of the IVC [3]. This is followed by formation of the paired supracardinal veins, which later separate into the superior and inferior portion of the azygos. The posterior cardinal veins undergo atrophy, and blood from the lower body passes through the supra subcardinal anastomosis into the prerenal IVC, while blood from the left body is sent across the inter postcardinal anastomosis [3].

In general, the normal IVC can be segmented into four main components; suprarenal, renal, infrarenal, and hepatic. Each portion develops from a distinct source. The right subcardinal vein develops into the suprarenal portion while the vitelline vein gives rise to the hepatic portion [3].

In interrupted IVC there is failure of development of one or 
more segment of IVC leading to abnormal pathway of draining of blood [3] (Figure 4).

Interrupted inferior vena cava arises when the right subcardinal vein fails to make its connection with the liver and shunts its blood directly into the right supracardinal vein (Figure $4 \mathrm{~A}$ and 4B). Hence the blood stream from the caudal part of the body reaches the heart by way of the azygos vein and superior vena cava. The hepatic vein enters into the right atrium at the site of the inferior vena cava. Usually this abnormality is associated with other heart malformations.

A double inferior vena cava occurs when the left sacro cardinal vein fails to lose its connection with the left subcardinal vein. And when supracardinal vein fails to regress it results in double IVC (Figure 4A and 5). The left common iliac vein may or may not be present, but the left gonadal vein remains as in normal site.

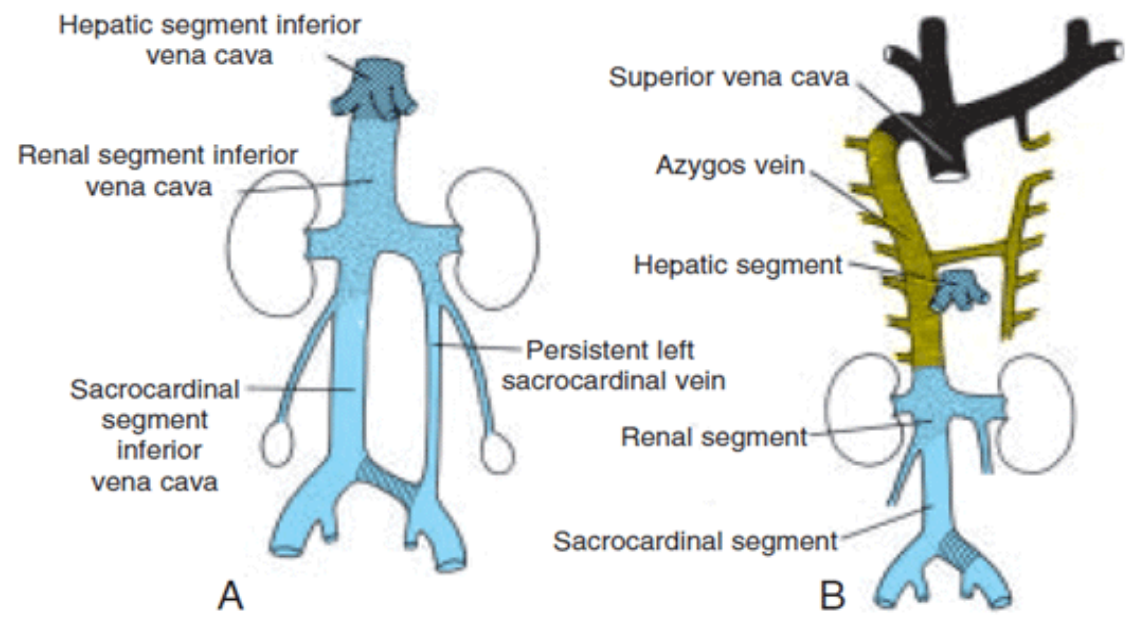

Figure 5:

\section{Surgical Importance}

- It is important to identify patients with interrupted IVC in cases of situs inversus. To prevent any injury to the abnormal vasculature, the exact location of vessels should be known. This variation becomes more important for surgical procedures like aortic bifurcational replacements, inferior caval shunt, and portal caval shunts [5]. An interrupted IVC can complicate retroperitoneal, thoracic and abdominal aortic aneurysm surgeries [4].

- Interrupted IVC \&Azygos continuation of IVC may complicate the lung resection surgery especially on right side.

- In the case of an azygos/hemiazygos continuation of the IVC, during venous cannulation for cardiopulmonary bypass, since there is no solid IVC trunk for placing the cannula, separate cannulation of the SVC and the right atrium is used [12].

- In cases of complete duplication of IVC patients may develop deep vein thrombosis and pulmonary thromboembolism making this variation even more clinically significant.

- Radiographically double IVC can be mistaken with a retroperitoneal mass or paravertebral lymph node enlargement $[10,11]$. Cases have been reported where such variants were confused with lymphadenopathy, aortic aneurysm and retroperitoneal cyst [7-9].

- Identification of double IVC is also important before renal transplantation and radical nephrectomy.

\section{Conclusion}

Interrupted inferior vena cava can be diagnosed with 2 Dimensional Echocardiography, angiography and confirmed with computed tomography scan and magnetic resonance imaging. Preoperative diagnosis of interrupted inferior vena cava helps in planning for surgeries involving cardiopulmonary bypass and surgeries involving IVC, abdominal aorta and renal transplantation. It also helps in management of associated diseases like deep vein thrombosis.

\section{References}

1. Phillips E. Embryology, normal anatomy, and anomalies.In Venography of the inferior vena cava and its branches. 1969;1-32.

2. Meyer R, Huppe T, Andresen R, Friedrich M. Intra- and infrahepatic agenesis of the inferior vena cava with azygos continuation accompanied by duplicationof the postrenal segment. Inrvest Radiol. 1998;33(2):113-116.

3. Bass JE, Redwine MD, Kramer LA, Huynh PT, Harris JH Jr. Spectrum of congenital anomalies of the inferior vena cava: cross-sectional imaging findings. Radiographics. 2000;20(3):639-652.

4. Dougherty MJ, Calligaro KD, DeLaurentis DA. Congenitally absent inferior vena cava presenting in adulthood with venous stasis and ulceration: a surgically treated case. J Vasc Surg. 1996;23(1):141146.

5. Milloy F, Anson BJ, Cauldwell EW. Variations in the inferior caval veins and in their renal and lumbar communications. Surg Gynecol Obstet. 1962;115:131-142. 
6. Abernathy J: Account of two instances of uncommon formationsin the viscera of the human body. Philosoph Trans. 1793; 83:59-66.

7. Chuang VP, Mena CE, Hoskins PA. Congenital anomalies of inferior vena cava: review of embryogenesis and presentation of a simplified classification. Br J Radiol. 1974;47(556):206-213.

8. Evans JC, Earis J, Curtis J. Thrombosed double inferior vena cava mimicking paraaortic lymphadenopathy. $\mathrm{Br} \mathrm{J}$ Radiol. 2001;74(878):192-194.

9. T.W Sadler. Langman embryology textbook. 9 th edition. Philadelphia: Lippincott williams and wilkins; 2005. p. 246-260.
10. Klimberg I, Wajsman Z. duplicated inferior vena cava simulating retroperitoneal lymphadenopathy in patients with embryonal cell carcinoma of testicle. J Urol. 1986;136(3):678-679.

11. Ng WT, Ng SS. Double inferior vena cava, a report of three cases. Singapore Med J. 2009;50(6):e211-213.

12.Wolfhard U, Splittgerber FH, Gocke P, Reidemeister JC. Bilateral Inferior Vena Cava With Azygos Continuation but Without Congenital Heart Disease Complicates Routine Venous Cannulation for Cardiopulmonary Bypass in an Adult. Thorac Cardiovasc Surg. 1997;45(1):40-42. 